\title{
Prevalence of Anaemia in Children Diagnosed with Pneumonia in a Tertiary Hospital in Quito, Ecuador
}

\author{
Garrido D', Fuseau $M^{2}$, Garrido $S^{3}$, Vivas G $^{4}$, Gutiérrez M $^{5}$
}

\section{Abstract}

Introduction: Anaemia and pneumonia are frequent diseases which affect children. However, these two conditions could coexist. The aim of this study is presenting the prevalence of anemia among Ecuadorian children diagnosed with pneumonia, hospitalized in a tertiary hospital. Material and Methods: An observational and cross-sectional study conducted through a secondary source in that 80 children, between six months and 15 years of age were included. All the patients involved were admitted to the paediatric department presenting pneumonia. The medical evaluation included anthropometric measurements and complete blood count. Risk associations were evaluated using odds ratio. Results: Anaemia was found in $21.25 \%$ of the whole group. Nonetheless, the children under three years of age were more affected by this condition (18.75\%). Low mean corpuscular volume and high red cells distribution width were more frequent than anaemia itself; $38.75 \%$ and $28.75 \%$, respectively. Additionally, the prevalence of anaemia in children under 36 months was higher than the patients with over three years, with a significant risk of anaemia in the first group (OR 13.04; $\mathrm{Cl} 95 \%$ 11.48-14.61; $p<0.05)$ and low haematocrit (OR 14.64; Cl 95\% 12.53-16.75; $p<0.05)$. This was also seen in low mean corpuscular volume (OR 3.23; Cl 95\% 2.3-4.17; $p<0.05$ ), high red cells distribution width (OR 2.77; $\mathrm{Cl} 95 \%$ 1.76-3.78; $p<0.05$ ), and mean corpuscular haemoglobin (OR 8.48; $\mathrm{Cl} 95 \%$ 7.14-9.82; $p<0.01)$. Conclusions: Anaemia is a frequent condition in paediatric pneumonia, particularly during the first three years of life. Therefore, anaemia or nutritional deficiencies could be a risk factor for respiratory diseases.

Key words: Anaemia; Ecuador; Paediatrics; Pneumonia

\section{Introduction}

W ith approximately 1.62 billion (25\%) people of the global population affected, anaemia is one of the most frequent diseases, primarily affecting people from developing or low-income countries. Furthermore, anaemia had become a significant public health problem that affects all ages of the world's population, with its highest prevalence among children under five years of age and pregnant women ${ }^{1}$. Anaemia is characterized by a wide variety of
1'David Garrido, Servicio de Oncohematología, Hospital Pediátrico Baca Ortiz, Quito, Ecuador, ${ }^{2}$ Michelle Fuseau, Posgrado de Reumatología, Universidad de la Republica, Montevideo, Uruguay, ${ }^{3}$ Santiago Garrido, Unidad de Cuidados Intensivos Instituto Ecuatoriano de Seguridad Social, Hospital General Ibarra, Ibarra, Ecuador, ${ }^{4}$ Gina Vivas, Servicio de Pediatría, Hospital de Especialidades de las Fuerzas Armadas $\mathrm{N}^{\circ} 1$, Quito, Ecuador, ${ }^{5}$ Miguel Gutiérrez, Servicio de Pediatría, Hospital de Especialidades de las Fuerzas Armadas $N^{\circ} 1$, Quito, Ecuador.

\section{Address for correspondence \\ David Israel Garrido Salazar \\ Servicio de Oncohematología, \\ Hospital Pediátrico Baca Ortiz, Dirección, 6 de Diciembre y Colón. Quito-Ecuador. \\ Tel No; +593984716214. \\ E-mail: david_labinmuno@hotmail.com.}

Acknowledgements: We thank the personnel of the HE-1 paediatrics department and Dr. Galo Fuseau from the department of clinical laboratory.

Funding: Nil

Conflict of Interest: None

Permission from IRB: Yes

How to cite

Garrido D, Fuseau M, Garrido S, Vivas G, Gutiérrez M. Prevalence of Anaemia in Children Diagnosed with Pneumonia in a Tertiary Hospital in Quito, Ecuador. J Nepal Paediatr Soc 2018;38(2):102-109.

doi:http://dx.doi.org/10.3126/jnps.v38i2.20193

This work is licensed under a Creative Commons Attribution 3.0 License. 
etiological factors. Some of these factors include the inadequate nutritional intake of micronutrients (vitamin B12, folate, and iron deficiencies), non-transmissible disorders, infectious diseases (HIVIAIDS, tuberculosis, malaria, helminths infections, and general inflammatory conditions), socioeconomic factors, and demographic circumstances, genetic and immuno-haematological disorders ${ }^{2}$. According to the World Health Organization (WHO), 50\% of an estimate of 293 million young children and 468 million non-pregnant women are affected by anaemia caused by iron deficiency; mostly due to inadequate iron intake ${ }^{(3)}$. In Ecuador, there are few studies which report the frequency of anaemia in children; however, it varies between $12 \%$ and $45 \%{ }^{4}$. As relevant as anaemia, malnutrition also affects our paediatric population. According to UNICEF, chronic malnutrition affects $25.3 \%$ of the Ecuadorian children ${ }^{5}$. In addition to this report, during the ninth epidemiological week of 2018 in Ecuador (From February 25th to March 3rd), 477 cases of acute malnutrition have been reported, of which $77.98 \%$ (372) cases correspond to moderate acute malnutrition, and $22.01 \%$ (105) cases correspond to severe acute malnutrition ${ }^{6}$.

Iron functions in the immune system are essential, among which are included: the maintenance of the activity of phagocyte oxidase; the increase of expression of the inducible nitric oxide synthase (iNOS). Similarly, intracellular iron promotes the activation of factor nuclear kappa B (NF-kB) and toll-like receptor 4 (TLR4) signaling ${ }^{7}$. Therefore, there is an association between iron deficiency and a reduced immune response to infection. On the other hand, an iron excess can be used by bacteria to improve its growth ${ }^{8}$. This association between iron and the immunological system could explain an increased risk of respiratory tract infection observed in children with iron deficiency anemia ${ }^{9}$. Pneumonia is a frequent disease in children; and with an approximate $17 \%$ of 6.3 million child deaths in 2010, was the leading cause of death in children in that year. Moreover, the pneumonia global incidence in children under five years old from low-income and middle-income countries was recently estimated as 0.22 episodes per child-year, of which $11.5 \%$ met criteria for severe disease ${ }^{10}$. In Latin America and the Caribbean, community-acquired pneumonia is a substantial cause of morbidity and mortality among children, with an estimated of 327,000 cases and 12,000-28,000 deaths annually ${ }^{11}$. This study aims to present the prevalence of anaemia and malnutrition among Ecuadorian children diagnosed with pneumonia, hospitalized in a tertiary hospital in Quito, Ecuador and to compare whether anaemia could have an impact on the length of hospital stay in pneumonic children.

\section{Material and Methods}

This observational and cross-sectional descriptive study was conducted at the Paediatrics Department of the Hospital of Specialties of the Armed Forces $N^{\circ} 1$ (Hospital de Especialidades de las Fuerzas Armadas No. 1 [HE-1]), from September 2017 to December 2017.

All the paediatric patients diagnosed with pneumonia, between July 2016 and September 2017, and its respective clinical history number using the logbooks from the Paediatrics Department. Through the software from the HE-1, the data recorded in the clinical history of each patient was extracted, which include the detailed clinical evaluation and all the complementary tests.

From the analysis of the HE-1 database, a total of 80 children, between six months up to 15 years of age were included. From a potential group of 100 patients, 20 children were excluded. The exclusion criteria for this study were: age outside the interval established for this work, lack of registered anthropometric parameters, absence of a complete blood count (CBC) at the admission to the hospital, diagnosis of concomitant conditions that could affect anthropometric or haemoglobin parameters, or that could predispose to pneumonia. No sample size determination was done, as all the children diagnosed with pneumonia were considered. As the anthropometric measurements and hematological parameters determination were perceived as part of the clinical evaluation of each patient, no experimentation was done during the clinical examination. Also, all the procedures were accomplished according to national and international guidelines, to arrive to an accurate diagnosis. Thus, there were no risks to the patients involved in this study.

Pneumonia diagnosis: The physical findings such as: fever, tachypnoea, breathing difficulties, rhonchi, crackles, and wheezing were used to establish a pneumonia diagnosis. Then, the evaluation of the hydration status, activity level, and oxygen saturation were essential for the decision of hospitalization and treatment ${ }^{12}$. According to World Health Organization (WHO), the tachypnea thresholds to diagnose pneumonia are: in children between two and 12 months, 50 breaths per minute (BPM) (Normal 25-40 BPM); 40 breaths for minute BPM in children between one and five years (Normal 20-30 BPM); and more than 20 BPM in children over five year's age ${ }^{13}$. Hypoxemia, defined as a sustained saturation of peripheral oxygen (SpO2) $<90 \%$, was used as criteria for hospitalization, along with criteria for respiratory distress, which includes: tachypnoea, dyspnoea, retractions (suprasternal, intercostal, or subcostal), grunting, nasal flaring, 
apnoea and altered mental status. Furthermore, CBC, acute-phase reactants and chest radiography were performed $^{14}$.

Body mass index: In determining the weight and height of the children involved in this work, was used the Seca 700 Physician's Balance Beam Scale with height rod and a minimum measurement of $50 \mathrm{~g}$ (Hospital code: HG-1-03646). Additionally, we used the Digital Baby Scale RL-DBS (Capacity: $20 \mathrm{~kg} \times 0.01 \mathrm{~kg}$, Platform Dimensions: $59.69 \times 27.94 \mathrm{~cm}$ ). The BMI was calculated using the Quetelet index $(\mathrm{BMI}=$ weight $[\mathrm{Kg}] /$ height $\left.^{2}\left[\mathrm{~m}^{2}\right]\right)$. After obtaining the BMI, all the children were classified according to the nutrition guidelines for the primary prevention and control of overweight and obesity in children and adolescents established by the Ministry of Public Health (Ministerio de Salud Pública [MSP]), which coincides with the WHO parameters ${ }^{15,16}$. Using the Z-score and percentile classification, the weight, height, and BMl were assessed for all the children included in this study. The anthropometric parameters were classified as follows: weight for age (severe low weight [Z score<-3], low weight [Z score<2], normal weight and high weight; height (severe low height [Z score<-3], low height [Z score<-2], normal and high height); and BMI (severely emaciated [ $Z$ score<3], emaciated [Z score $<-2$ ], overweight [ $Z$ score $>2$ ] and obesity [Z score $>3]$ ) (16). Under two years of age, we used the weight-for-length charts.

Determination of haematological parameters: Haematological parameters were determined through an auto haematology analyser Mindray BC-6800, which uses a $3 \mathrm{D}$ analysis obtaining information from scattering of laser light at two angles and fluorescence signals, as well as a colorimetric method to measure haemoglobin.

Anaemia diagnosis: To diagnose anaemia, we based our criteria on the haemoglobin values suggested by the WHO, when the levels were below the normal for age. Additionally, we used haemoglobin correction according to the geographical residence, as advised by the WHO ${ }^{(17)}$. We also included in the analysis other haemato-metric parameters presented by the $\mathrm{CBC}$, such as haematocrit (HCT), mean corpuscular volume (MCV), mean corpuscular haemoglobin $(\mathrm{MCH})$, and red cell distribution width (RDW). The corresponding normal values considered in this study are shown in Tables 1 and $2^{18}$

In the present study, the exposure factor was anaemia or early markers of iron deficiency such as high RDW or low MCV. Therefore, two patient groups were included in the study, one of which was anaemic patients diagnosed with pneumonia, and the other was non-anaemic patients diagnosed with pneumonia. There were variables beyond the control of this study, such as ethnic differences, iron intake and poverty status. No cases of cigarette usage or pregnancy were founded.

The clinical data were analysed using SPSS software and Excel, both in their latest versions for Windows 10. The risk association between anaemia and pneumonia was calculated through the odds ratio (OR). To contrast the length of hospital stay among de different conditions studied we used the Mann-Whitney $\mathrm{U}$ Test. Also, we used convenience sampling.

\section{Results}

From a total of 80 patients, we found $47.50 \%$ of them being under three years of age. In spite of we classified the patients into two groups according to the age (minors and over three years), we observed that 29 were under 24 months, 19 between two and three years, 18 between four and six years, and the remaining ones were between seven and 15 years. Besides, there was an average age of 3.98 years (SD 3.35; Cl 3.25-4.72).

In the whole group of participants, the percentage of female children was higher than males $(51.25 \%$ vs. $48.75 \%$, respectively). In addition to this, we observed that $31.25 \%$ of the participants suffered a previous episode of pneumonia.

Nutritional status: The most frequent nutritional problem observed in our studied population was low weight $(16.25 \%)$, being more common in children under three years of age. However, we found anthropometric parameters under Z-score -1 (Weight Z score <-1, $40 \%$; Height Z score <-1, 33.75\%; BMI Z score <-1, $30 \%)$. Both, severe low weight and severe low height were observed in $3.75 \%$ of the patients. There were no children severely emaciated.

Anaemia prevalence: Anaemia was found in $21.25 \%$ of the whole group. However, the children under three years of age were more affected by this condition $(18.75 \%)$. Early markers of iron deficiency, such as mean corpuscular volume and red cells distribution width were more frequent that anaemia itself; $38.75 \%$ and $28.75 \%$, respectively.

Risk of anaemia in toddlers: When the prevalence of anaemia was compared between children under 36 months old (toddlers) and the patients with age over three years, we found a significant risk of anemia in the first group (OR 13.04; Cl 95\% 11.48-14.61; $p<0.05$ ) and low HCT (OR 14.64; Cl 95\% 12.53-16.75; $p<0.05$ ). This pattern was also seen in the early markers of iron deficiency, low MCV (OR 3.23; CI 95\% 2.3-4.17; $p<0.05$ ), high RDW (OR 2.77; Cl 95\% 1.76-3.78; $p<0.05$ ), and $\mathrm{MCH}$ (OR 8.48; Cl 95\% 7.14-9.82; $p<0.01$ ) 
Risk association between the anthropometric variables and anaemia: We didn't observe any risk association when the anthropometric variables were considered as exposure factor to suffer anaemia.
Length of hospital stay: We found no significant difference in the length of hospital stay during the comparison of various conditions. Table 4 presents the average number of days that the patients included in this study stayed in HE-1. No cases of death were reported.

Table 1: Normal values of the haemogram used in this study

\begin{tabular}{cccccc}
\hline Age & HB $(\mathbf{g} / \mathbf{l})$ & HTC (\%) & MCV (fl) & MCH (pg) & RDW (\%) \\
\hline 6 months & 110 or higher & $34-40$ & $74-108$ & $25-35$ & $10.8-14.2$ \\
\hline 1 year to 59 moths & 110 or higher & $35-42$ & $74-86$ & $25-31$ & $11.6-15.6$ \\
\hline 5 years & 115 or higher & $35-42$ & $75-87$ & $25-33$ & $11.6-14.0$ \\
\hline 6 to 11 years & 115 or higher & $35-47$ & $77-91$ & $25-33$ & $11.6-14.0$ \\
\hline 12 to 15 years & 120 or higher & $35-48$ & $77-95$ & $25-33$ & $11.6-14.0$ \\
\hline
\end{tabular}

Abbreviations; HB: haemoglobin; HTC: haematocrit; MCV: mean corpuscular volume; $\mathrm{MCH}$ : mean corpuscular haemoglobin; RDW: red cell distribution width; g/l: grams per litre; fl: fentolitre; pg: picogram.

Table 2: Altitude adjustments according to place of residence

\begin{tabular}{cc}
\hline Altitude (masl) & HB adjustment $(\mathbf{g} / \mathbf{l})$ \\
\hline$<1000$ & 0 \\
\hline 1000 & -2 \\
\hline 1500 & -5 \\
\hline 2000 & -8 \\
\hline 2500 & -13 \\
\hline 3000 & -19 \\
\hline 3500 & -27 \\
\hline 4000 & -35 \\
\hline 4500 & -45 \\
\hline
\end{tabular}

Abbreviation; Masl: meters above sea level; HB: haemoglobin; g/l: grams per litre.

Table 3A: Showing general characteristics of the groups and primary results of this work.

\begin{tabular}{cccccccc}
\hline & & \multicolumn{2}{c}{ Age $<3$ years } & \multicolumn{2}{c}{ Age $\geq \mathbf{3}$ years } \\
\hline & $\mathbf{n}$ & $\%$ & $\mathbf{n}$ & $\%$ & $\mathbf{n}$ & \% \\
\hline Total & 80 & 100.00 & 38 & 47.50 & 42 & 52.50 \\
\hline Male & 39 & 48.75 & 18 & 22.50 & 21 & 26.25 \\
\hline Female & 41 & 51.25 & 20 & 25.00 & 21 & 26.25 \\
\hline Previous Pneumonia & 25 & 31.25 & 9 & 11.25 & 16 & 20.00 \\
\hline
\end{tabular}

Table 3B: Showing various anthropometric measurements

\begin{tabular}{|c|c|c|c|c|c|c|}
\hline \multirow{2}{*}{ Anthropometric variables } & \multicolumn{2}{|c|}{ Total } & \multicolumn{2}{|c|}{ Age $<3$ years } & \multicolumn{2}{|c|}{ Age $\geq 3$ years } \\
\hline & $\mathbf{n}$ & $\%$ & $\mathbf{n}$ & $\%$ & $\mathbf{n}$ & $\%$ \\
\hline Weight ( $Z$ score under -1$)$ & 32 & 40.00 & 19 & 23.75 & 13 & 16.25 \\
\hline Height ( $Z$ score under -1 ) & 27 & 33.75 & 15 & 18.75 & 12 & 15.00 \\
\hline $\mathrm{BMI}^{*}(\mathrm{Z}$ score under -1$)$ & 24 & 30.00 & 11 & 13.75 & 13 & 16.25 \\
\hline Weight ( $Z$ score under -2 ) & 13 & 16.25 & 8 & 10.00 & 5 & 6.25 \\
\hline Height ( $Z$ score under -2 ) & 7 & 8.75 & 3 & 3.75 & 4 & 5.00 \\
\hline $\mathrm{BMI}^{*}$ (Z score under -2$)$ & 6 & 7.50 & 3 & 3.75 & 3 & 3.75 \\
\hline
\end{tabular}


Table 3C: Showing haematological paramenters

\begin{tabular}{cccccccc}
\hline Hematologic variables & \multicolumn{2}{c}{ Total } & \multicolumn{2}{c}{ Age $<3$ years } & \multicolumn{2}{c}{ Age $\geq 3$ years } \\
\cline { 2 - 8 } & $\mathbf{n}$ & $\mathbf{0}$ & $\mathbf{n}$ & $\%$ & $\mathbf{n}$ & $\%$ \\
\hline Anaemia & 17 & 21.25 & 15 & 18.75 & 2 & 2.50 \\
\hline Low HCT & 11 & 13.75 & 10 & 12.50 & 1 & 1.25 \\
\hline Low MCV & 31 & 38.75 & 20 & 25.00 & 11 & 13.75 \\
\hline Low MCH & 18 & 22.50 & 15 & 18.75 & 3 & 3.75 \\
\hline High RDW & 23 & 28.75 & 15 & 18.75 & 8 & 10.00 \\
\hline
\end{tabular}

Abbreviations; BMI: body mass index; ${ }^{*}$ n children under 2 years of age was used the Weight-for-length charts; HCT: haematocrit; MCV: mean corpuscular volume; $\mathrm{MCH}$ : mean corpuscular haemoglobin; RDW: red cell distribution width; The values of the haematological variables were assigned according to the reference range established in the methods section.

Table 4: Showing length of hospital stay

\begin{tabular}{|c|c|c|c|c|c|c|c|}
\hline Comparison & Variables & $\begin{array}{c}\text { Average of hospital } \\
\text { stay days }\end{array}$ & SD & $\begin{array}{c}\max \\
\text { (days) }\end{array}$ & $\begin{array}{c}\text { min } \\
\text { (days) }\end{array}$ & z-score* & $p$-value \\
\hline \multirow{2}{*}{1} & Age $<3$ years & 4.90 & 1.39 & 8 & 2 & -0.37 & $>0.05$ \\
\hline & Age $\geq 3$ years & 4.97 & 1.73 & 10 & 3 & & \\
\hline \multirow[t]{2}{*}{2} & Anemia & 4.71 & 1.65 & 9 & 3 & -1.98 & $>0.05$ \\
\hline & No anemia & 5.00 & 1.53 & 10 & 2 & & \\
\hline \multirow{2}{*}{3} & Low HCT & 4.64 & 1.91 & 9 & 3 & -2.14 & $>0.05$ \\
\hline & Normal & 4.99 & 1.50 & 10 & 2 & & \\
\hline \multirow{2}{*}{4} & Low MCV & 5.13 & 1.77 & 10 & 3 & 0.44 & $>0.05$ \\
\hline & Normal & 4.82 & 1.41 & 8 & 2 & & \\
\hline \multirow{2}{*}{5} & Low MCH & 5.29 & 1.93 & 10 & 3 & 0.62 & $>0.05$ \\
\hline & Normal & 4.84 & 1.44 & 9 & 2 & & \\
\hline \multirow{2}{*}{6} & High RDW & 5.13 & 1.77 & 10 & 3 & -0.57 & $>0.05$ \\
\hline & Normal & 4.82 & 1.41 & 8 & 2 & & \\
\hline
\end{tabular}

Abbreviations; SD, standard deviation; max, maximum value; min, minimum value; $\mathrm{HCT}$, haematocrit; MCV, mean corpuscular volume; $\mathrm{MCH}$, mean corpuscular haemoglobin, RDW, red cell distribution width; The values of the haematological variables were assigned according to the reference range established in the methods section, ${ }^{*} z$-score obtained through Mann-Whitney $U$ Test.

\section{Discussion}

Anaemia is a disease which is a public health problem in children under six years of age in Latin America and the Caribbean, and is considered a moderate health problem (prevalence of anaemia between $20 \%$ and $40 \%$ ) in Nicaragua, Brazil, Mexico, Ecuador, El Salvador, Cuba, Colombia, Dominican Republic, Peru, Panama, Honduras, and Guatemala ${ }^{19}$. According to the ENSANUT-ECU 2012 (Encuesta Nacional de Salud y Nutrición-Ecuador 2012, National Health and Nutrition Survey-Ecuador 2012), the prevalence of anaemia was $25.7 \%$ in children; but, in the indigenous community, percentage reported reached $41.6 \%{ }^{20}$. These reports are similar to our findings. However, our anaemia prevalence is slightly lower than the ENSANUT-ECU 2012.

It is necessary to remark that we observed a higher prevalence of markers that are present in the early stages of iron deficiency anaemia, rather than the prevalence of anaemia itself, defined as low haemoglobin. One of these markers was RDW, which was described as a highly sensitive and useful tool for early diagnosis of mild iron deficiency anaemia ${ }^{21}$. Also, it was recommended as a valuable tool for the determination of iron deficiency anaemia in early stages. Furthermore, low MCV was even more frequent that high RDW in our population, something significant because an isolated low MCV could indicate an initial phase of iron deficiency by itself. However, these two fundamental tools, RDW and $\mathrm{MCV}$, could frequently be missed during the paediatric evaluation $^{22}$. The group of children under three years was most frequently affected by anaemia, a finding that could be explained because, through the first 24 months of life, children have an increased risk to suffer anaemia, related to the active growth and the resulting increased need for iron per kilogram of body weight. Also, after six months of age, children need to get increasing quantities of iron from food, which is subject to various absorption limitations ${ }^{23}$. 
Another notable finding was that approximately the half of patients included in our study were under three years of age, similarly as the globally observed. Additionally, there was a documented high mortality by respiratory tract infection in children less than five years of age in developing countries, who are affected by poor nutritional status ${ }^{24}$. If an inadequate dietary intake is a risk factor to suffer pneumonia, then, iron deficiency could also be suggested as a potential risk factor for respiratory tract infections. For example, a study conducted in Chile reported $20 \%$ of anaemia in children diagnosed with chronic respiratory diseases, just as we observed, approximately $20 \%$ of our patients diagnosed with pneumonia have anaemia. However, is necessary to remark this risk association in children under 32 months of age ${ }^{25}$. The significant risk association between anaemia and pneumonia in children was also described in other studies. One of them conducted in the paediatric department of the Al-Azhar university hospital found a significant decrease of RBCs, haemoglobin, ferritin, and iron in children diagnosed with pneumonia ${ }^{26}$. Additionally, a study which includes 200 infants and children between nine months to 16 years, found that anaemic subjects were 5.7 times more susceptible to low respiratory tract infections, as well as, what was described in a study conducted in the paediatric department of Manipal Teaching Hospital, which shows anaemic children were 3.2 times more susceptible to acute low respiratory tract infections $(p<0.01)^{27,28}$. A meta-analysis published in 2013, presents a series of risk factors for severe acute lower respiratory infections in children described by odds ratios (with 95\% confidence intervals): low birth weight 3.18 (1.02-9.90), lack of exclusive breastfeeding 2.34 (1.42-3.88), crowding-more than seven persons per household 1.96 (1.53-2.52), exposure to indoor air pollution 1.57 (1.06-2.31), incomplete immunization 1.83 (1.32-2.52), undernutrition-weight-for-age less than 2 standard deviations 4.47 (2.10-9.49), and HIV infection 4.15 (2.57-9.74). All, of these risk factors, should be considered in subsequent studies to clarify the importance of iron deficiency anaemia as a risk factor for pneumonia ${ }^{29}$. In spite of these findings, a study which includes 12 infants and children below five years of age observed no influence of anaemia as a risk factor for pneumonia ${ }^{30}$.

The iron homeostasis is essential during immune responses as the reduction in its availability by proteins like hepcidin, decreases the bacterial growth. On the other hand, iron is required in cytokine production as well as participates in enzymatic phenomena like the activity of myeloperoxidase or even has been demonstrated quantitatively altered $\mathrm{T}$ cell subsets in iron deficiency in children ${ }^{31}$. If we consider the importance of iron in immunology, is justified in thinking that anaemia could be present in other infectious diseases. A study carried out in 293 children showed anaemia $(\mathrm{Hb}<11 \mathrm{~g} / \mathrm{dl})$ at six months was an independent risk factor for diarrhoea and respiratory disease in children with age between 7 to 18 months $^{32}$. Similarly, in a previous study in which we studied the clinical characteristics of the urinary tract infection caused by Escherichia coli in the HE-1, in children between three months and 14 years of age, we found haemoglobin under 11.8 in $32.4 \%$ and $40 \%$, of the patients admitted in the hospital and the external consultation, respectively ${ }^{33}$.

We found a similar time of hospital stay among different conditions in our patients, something that could be explained because, with the antibiotic, pharmacological and no pharmacological support, the difference between the groups compared is reduced.

This research has significant limitations that should be considered; one of them is the reduced number of patients. So, it is necessary to expand the number of subjects. Another weakness is the point that we only considered data from our hospital for the analysis. Thus, it is essential to employ data from other health institutions for further studies to understand the influence of iron deficiency in lower respiratory tract infection in our population. Also, as we did not include ferritin levels in each patient, it would be interesting to analyse all the wide range of iron deficiency markers in children.

\section{Conclusion}

Our results suggest anaemia as a frequent condition in children diagnosed with pneumonia, particularly during the first three years of life. Therefore, a detailed evaluation of patients in this group of age, which includes, nutritional assessment, is needed in both, hospital and primary health care. We suggest for new studies to study in detail the association between iron deficiency markers and pneumonia, as well as other infectious diseases, especially in children under 36 months. It is essential also to consider the appropriate establishment of therapeutic algorithms to guarantee a rational use of antibiotics 


\section{References}

1. Asrie F. Prevalence of anemia and its associated factors among pregnant women receiving antenatal care at Aymiba Health Center, northwest Ethiopia. J Blood Med 2017;8:35-40. DOI: 10.2147/JBM.S134932

2. Jamali $\mathrm{NH}$, Mahesar $\mathrm{H}$, Bhutto MA. Prevalence of Iron Deficiency Anaemia in School and College Going Students of District Shaheed Benazirabad Sindh Province, Pakistan. OJBD 2016;6:67-78. DOI: 10.4236/ojbd.2016.64010

3. Chandyo RK, Henjum S, Ulak M, Thorne- Lyman AL, Ulvik RJ, Shrestha PS, et al. The prevalence of anemia and iron deficiency is more common in breastfed infants than their mothers in Bhaktapur, Nepal. Eur J Clin Nutr 2016:70;456-62. DOI: 10.1038/ejcn.2015.199

4. Quizhpe E, San Sebastian M, Karin Hurtig A, Llamas A. Prevalencia de anemia en escolares de la zona amazónica de Ecuador / Prevalence of anemia in schoolchildren of the Amazon area of Ecuador. Rev Panam Salud Publica 2003;13(6):355-61. http://iris. paho.org/xmlui/handle/123456789/8431

5. United Nations International Children's Emergency Fund (UNICEF) [Internet]. Quito, Ecuador: United Nations International Children's Emergency Fund; [cited 2018 april 30]. Available on: https://www.unicef. org/ecuador/alianzas_para_la_nutricion.pdf

6. Ministerio de Salud Pública del Ecuador (MSP). Gaceta Desnutrición Semana 09-2018 [Internet]. Quito, Ecuador. Ministerio de Salud Pública del Ecuador; [cited 2018 april 30]. Available on: http:// www.salud.gob.ec/wp-content/uploads/2016/09/ GACETA-DESNUTRICI\%C3\%93N-SE-09_2018.pdf

7. Cherayil BJ. Iron and immunity: immunological consequences of iron deficiency and overload. AITE 2010;58(6):407-15. DOI: 10.1007/s00005-010-0095-9.

8. Kumar V, Choudhry VP. Iron Deficiency and Infection. Indian J Pediatr 2010; 77(7):789-93. DOI: 10.1007/ s12098-010-0120-3

9. Mourad S, Rajab M, Alameddine A, Fares M, Ziade F, Merhi BA. Hemoglobin level as a risk factor for lower respiratory tract infections in Lebanese children. N Am J Med Sci 2010;2(10):461-6. DOI: 10.4297/ najms.2010.2461.

10. Rudan, I, O'Brien, KL, Nair, $\mathrm{H}$ et al. Epidemiology and etiology of childhood pneumonia in 2010: estimates of incidence, severe morbidity, mortality, underlying risk factors and causative pathogens for 192 countries. J Glob Health 2013;3:010401. DOI: 10.7189/ jogh.03.010401.

11. Gentile A, Bardach A, Ciapponi A, Garcia-Marti S, Aruj $P$, Glujovsky D, et al. Epidemiology of communityacquired pneumonia in children of Latin America and the Caribbean: a systematic review and meta-analysis. Int J Infect Dis. 2012;16(1):e5-15. DOI: 10.1016/j. ijid.2011.09.013
12. Stuckey-Schrock K, Hayes BL, George CM. Community-Acquired Pneumonia in Children. Am Fam Physician 2012;86(7):661-7. https://www.aafp.org/ afp/2012/1001/p661.html

13. World Health Organization. The Management of Acute Respiratory Infections in Children: Practical Guidelines for Outpatient Care. Geneva, Switzerland: World Health Organization; 1995. [cited 2018 april 30]. Available on: http://apps.who.int/iris/bitstream/ handle/10665/41803/9241544775_eng.pdf;jsessionid =FF4E4FECF1B868AE3520F6A8F416F0A3?sequen $\mathrm{ce}=1$

14. Bradley JS, Byington CL, Shah SS, Alverson B, Carter ER, Harrison C, et al. Executive Summary: The Management of Community-Acquired Pneumonia in Infants and Children Older Than 3 Months of Age: Clinical Practice Guidelines by the Pediatric Infectious Diseases Society and the Infectious Diseases Society of America. Clinical Infectious Diseases: Clin Infect Dis 2011;53(7):617-30. DOI: 10.1093/cid/cir531

15. Torres-Tamayo M, Aguilar-Herrera BE, AltamiranoBustamante $N$, Barquera $S$, Barrientos-Pérez $M$, Bracho-Blanchet $\mathrm{E}$, et al. Consenso de expertos sobre prevención, diagnóstico y tratamiento de la obesidad en edad pediátrica. Bol Med Hosp Infant Mex 2015;72(1):1-28. http://www.elsevier.es/esrevista-boletin-medico-del-hospital-infantil-401pdf-X1665114615342123

16. salud.gob.ec. Unidad de Nutrición, Guías y Manuales. [Internet]. Ecuador: Ministerio de Salud Pública del Ecuador; c2017 [cited 2017 Jul 10]. Available from: http://www.salud.gob.ec/unidad-de-nutricion-guias-ymanuales/who.int.

17. Concentraciones de hemoglobina para diagnosticar la anemia y evaluar su gravedad. [Home page in Internet]. Ginebra: Organización Mundial de la Salud; [cited 2017 Dec 17]. Available from: http://www.who. int/vmnis/indicators/haemoglobin_es.pdf

18. Díaz de Heredia C, Bastida P. Interpretación del hemograma pediátrico. An Pediatr Contin 2004;2(5):291-6. http://www.apcontinuada.com/ es/interpretacion-del-hemograma-pediatrico/ articulo/80000081/

19. Mujica-Coopman MF, Brito A, López de Romaña D, Ríos-Castillo I, Coris H, Olivares M. Prevalence of Anemia in Latin America and the Caribbean. Food Nutr Bull 2015;36(2):S119-28. DOI: 10.1177/0379572115585775

20. Freire WB, Ramírez-Luzuriaga MJ, Belmont $P$, Mendieta MJ, Silva-Jaramillo MK, Romero N, et al. Tomo I: Encuesta Nacional de Salud y Nutrición de la población ecuatoriana de cero a 59 años. ENSANUTECU 2012. Ministerio de Salud Pública/Instituto Nacional de Estadísticas y Censos 2014; p. 41-429. http://www.ecuadorencifras.gob.ec/documentos/ web-inec/Estadisticas_Sociales/ENSANUT/MSP ENSANUT-ECU_06-10-2014.pdf 
21. Sharma A, Sharma M, Sharma V. Evaluation of red cell distribution width in the diagnosis of iron deficiency anemia. Int J Res Med Sci 2016;4(9):3733-6. DOI: 10.18203/2320-6012.jirms20162603

22. Subramanian DN, Kitson S, Bhaniani A. Microcytosis and possible early iron deficiency in paediatric inpatients: a retrospective audit. BMC Pediatr 2009;9(39). DOI: 10.1186/1471-2431-9-36.

23. Silva DG, Priore SE, Franceschini S do CC. Risk factors for anemia in infants assisted by public health services: the importance of feeding practices and iron supplementation. J Pediatr (Rio J) 2007;83(2):149-56. DOI: 10.2223/JPED.1603

24. Ramezani M, Aemmi SZ, Moghadam ZE. Factors Affecting the Rate of Pediatric Pneumonia in Developing Countries: a Review and Literature Study. Int J Pediatr 2015;3:1173-81. DOI: 10.22038/IJP.2015.6179

25. Barja S, Capo E, Briceño L, Jakubson L, Méndez M, Becker A. Anemia y déficit de hierro en niños con enfermedades respiratorias crónicas. Nutr. Hosp. 2013; 28(3):787-793. DOI:10.3305/nh.2013.28.3.6452

26. Abdel-Maksoud HM, Hasan KA, Helwa MA. Evaluation of Iron Deficiency Anemia as a Predisposing Factor in the Occurrence of Pneumonia in Children. Trends Med Res 2016;11:69-75. DOI: 10.3923/tmr.2016.69.75

27. Ramakrishnan K. Harish PS. Hemoglobin level as a risk factor for lower respiratory tract infections. Indian $\mathrm{J}$ Pediatr 2006;73:881-3. http://medind.nic.in/icb/t06/i10/ icbt06i10p881.pdf
28. Malla T, Pathak OK, Malla KK. Is low hemoglobin level a risk factor for acute lower respiratory tract infections? J Nepal Pediatr Soc 2010;30:1-7. DOI: 10.3126/jnps. v30i1.2453

29. Jackson S, Mathews KH, Pulanić D, Falconer R, Rudan I, Campbell H, et al. Risk factors for severe acute lower respiratory infections in children - a systematic review and meta-analysis. Croat Med J 2013;54(2):110-21. DOI: $10.3325 / \mathrm{cmj} .2013 .54 .110$

30. Broor S, Pandey RM, Ghosh M, Maitreyi RS, Lodha $R$, Singhal $T$, et al. Risk factors for severe acute lower respiratory tract infection in under-five children. Indian Pediatr 2001;38(12):1361-9. https://www. indianpediatrics.net/dec2001/dec-1361-1369.htm

31. Mullick S, Rusia U, Sikka M, Faridi MA. Impact of iron deficiency anaemia on $T$ lymphocytes \& their subsets in children. Indian J Med Res. 2006 Dec;124(6):64729. https://www.ncbi.nlm.nih.gov/pubmed/17287552

32. Levy A, Fraser D, Rosen SD, Dagan R, Deckelbaum $\mathrm{RJ}$, Coles $\mathrm{C}$, et al. Anemia as a risk factor for infectious diseases in infants and toddlers: results from a prospective study. Eur J Epidemiol 2005;20(3):277-84. DOI: 10.1007/s10654-004-6515-6

33. Garrido D, Garrido S, Gutiérrez M, Calvopiña L, Harrison AS, Fuseau M, et al. Clinical characterization and antimicrobial resistance of Escherichia coli in pediatric patients with urinary tract infection at a third level hospital of Quito, Ecuador. Bol Med Hosp Infant Mex 2017;74(4):265-71. DOI: 0.1016/j. bmhimx.2017.02.004. 